\title{
Dosage Optimization of Polypropylene Fiber for Strength Enhancement of Cementitious Composites
}

\author{
Mohammad R. Irshidat \\ mirshidat@qu.edu.qa \\ Center for Advanced Materials, Qatar University, Doha, Qatar \\ Nasser Al Nuaimi \\ anasser@qu.edu.qa \\ Center for Advanced Materials, Qatar University, Doha, Qatar \\ Soheb Salim \\ sohebsalim93@gmail.com \\ Department of Civil and Architectural Engineering, Qatar University, Doha, Qatar \\ Mohamed Rabie \\ m.rabie@qu.edu.qa \\ Department of Civil and Architectural Engineering, Qatar University, Doha, Qatar
}

\begin{abstract}
Concrete is the most commonly used materials for construction in Qatar as well as in the world. Exposure to sever environmental conditions causes physical deterioration of concrete structures and significantly affect the concrete's strengths and modulus of elasticity. In the last decades, many improvements had been made in concrete technology. Most of these improvements focused on the weak point of concrete, which is tensile strength enhancement. One possible method to improve the tensile strength of cementitious composites is incorporation of fibers in the mix. Polypropylene fiber is widely used for this purpose due to their corrosion resistance and relatively low cost. Polypropylene fibers are usually incorporated in cement mortar to control cracks propagation thus enhance its tensile and flexural properties. This research focuses on Polypropylene fiber dosage optimization for strength enhancement of cementitious composites. Four dosages of Polypropylene microfibers; $0 \%, 0.05 \%, 0.1 \%$, and $0.2 \%$ by weight of cement; were added into cement mortar to explore the optimum dosage that can lead to big enhancement in mechanical strengths of cementitious composites. The mechanical strengths were investigated in terms of compressive and flexural strengths. The results revealed that adding small amount of Polypropylene microfibers could enhance the compressive and flexural strengths of cement mortar. The maximum enhancement in the compressive and flexural strengths was equal to $26 \%$ and $19 \%$ and was achieved in the case of adding $0.1 \%$ and $0.05 \%$ by weight of cement, respectively.
\end{abstract}

Keywords: Polypropylene fiber; Mortar; Optimization; Compressive strength; Flexural strength

\section{INTRODUCTION}

Concrete is the most common used materials for construction in Qatar as well as in the world. Exposure to sever environmental conditions causes physical deterioration of concrete structures and significantly affect the concrete's strengths and modulus of elasticity. In the last decades, many improvements had been made in concrete 
technology. Most of these improvements focused on the weak point of concrete, which is tensile strength enhancement. Failure in cementitious materials is a gradual multiscale process. When loaded, initially short and discontinuous micro cracks are created in a distributed manner. These micro cracks merge to form macro cracks. To avoid the failure in cementitious materials, the growth of the cracks should be stopped to delay the coalescence of cracks or even to prevent the cracks' initiation at all.

One possible method to mitigate the crack propagation and enhance the tensile strength of cementitious composites is incorporation of fibers in the mix. Polypropylene fiber is widely used for this purpose due to their corrosion resistance and relatively low cost. Polypropylene fibers are usually incorporated in cement mortar to control cracks propagation thus enhance its tensile and flexural properties (Li et al., 2018; Li et al., 2018; Mohseni et al., 2016; Nunes et al., 2019; Szelag et al., 2019; Zanotti et al., 2017).

This research focuses on Polypropylene fiber dosage optimization for strength enhancement of cementitious composites. Four dosages of Polypropylene microfibers; $0 \%, 0.05 \%, 0.1 \%$, and $0.2 \%$ by weight of cement; were added into cement mortar to explore the optimum dosage that can lead to big enhancement in mechanical strengths of cementitious composites. The mechanical strengths were investigated in terms of compressive and flexural strengths.

\section{EXPERIMENTAL PROGRAM}

\subsection{Materials}

Portland cement, locally available silica sand, and tap water were used to prepare the cement mortar used in this research. Commercially available polypropylene micro fibers were used to modify the cementitious matrix. The fibers' length, diameter, and density are two millimeters, thirty-four micrometers, and $910 \mathrm{~kg} / \mathrm{m} 3$.

\subsection{Specimens preparation}

Cement mortar was prepared according to the ASTM C305 mixing procedure. Four batches of cement mortar were prepared. One batch was prepared as a control sample of plain cement mortar (water, sand, and cement). The other batches were prepared with various percentages of fibers $0.05 \%, 0.1 \%$, and $0.2 \%$ by weight of cement. A binder/sand ratio of $1: 3$ and water/binder $(\mathrm{w} / \mathrm{b})$ ratio of 0.55 were used to prepare all batches. After mixing, the mortar mixtures were molded into $5 \mathrm{~cm}$ cubes for compressive strength and $4 \mathrm{~cm} \times 4 \mathrm{~cm} \times 16 \mathrm{~cm}$ prisms for flexural strength tests. Twenty-four hours later, all samples were taken out of molds, and then cured in a bath of lime-saturated water. Twenty-eight days later, the specimens were taken out from the lime-saturated water bath and left to dry, then tested.

\subsection{Test procedures}

The compressive and flexural strength tests were conducted according to the ASTM C109 and ASTM C348 standards, respectively. Three specimens of each formulation were tested, and the average strengths were calculated.

\section{RESULTS AND DISCUSSION}

The compressive and flexural strength values of cement mortars as a function of 
polypropylene fiber dosage are shown in Figure 1 and Figure 2, respectively. The enhancements in the strengths are tabulated in Table 1. The results reveal that adding polypropylene fibers enhanced the compressive strength of the cement mortar. Maximum enhancement of $26 \%$ compared to the control specimen was observed in the case of using $0.1 \%$ fibers content. On the other hand, adding polypropylene fibers enhanced the flexural strength of the cement mortar. The enhancement increases with increasing the amount of added fibers. Maximum enhancement of 19\% compared to the control specimen was observed in the case of using $0.05 \%$ fibers content. The strength enhancement may be attributed to the fact that the polypropylene fibers delay the initiation and propagation of the micro cracks due to the well distributed within the cement mortar. Adding micro fibers may lead to enhance the adhesion between the hydration products and thus improve the mechanical strengths of the mortar.

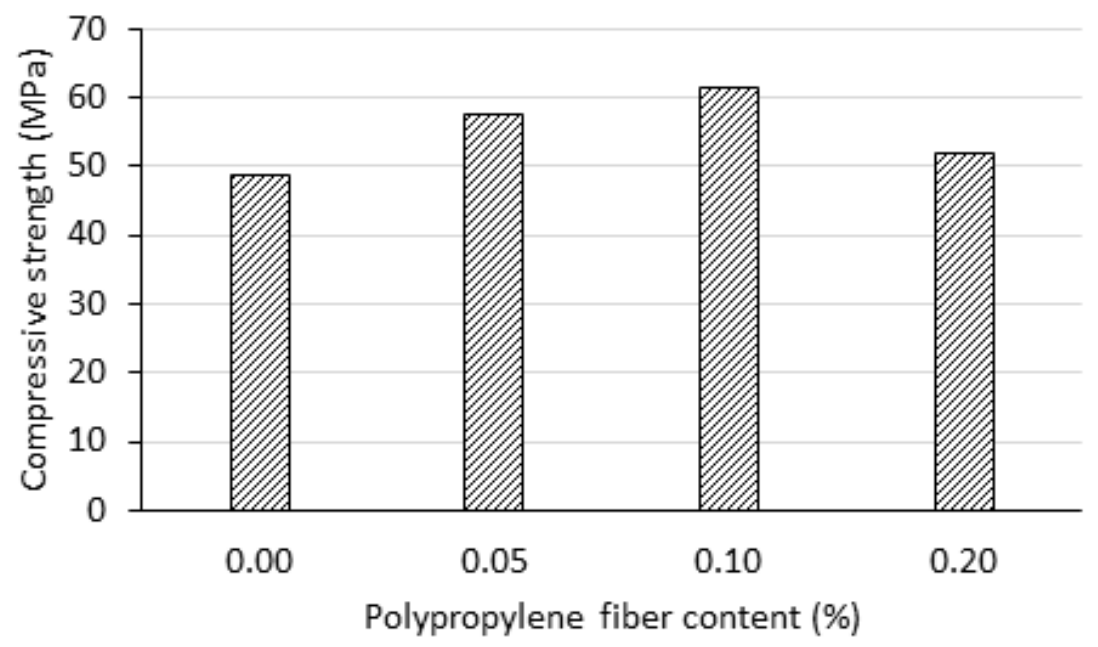

Figure 1: Compressive strength of cement mortar with Polypropylene fibres

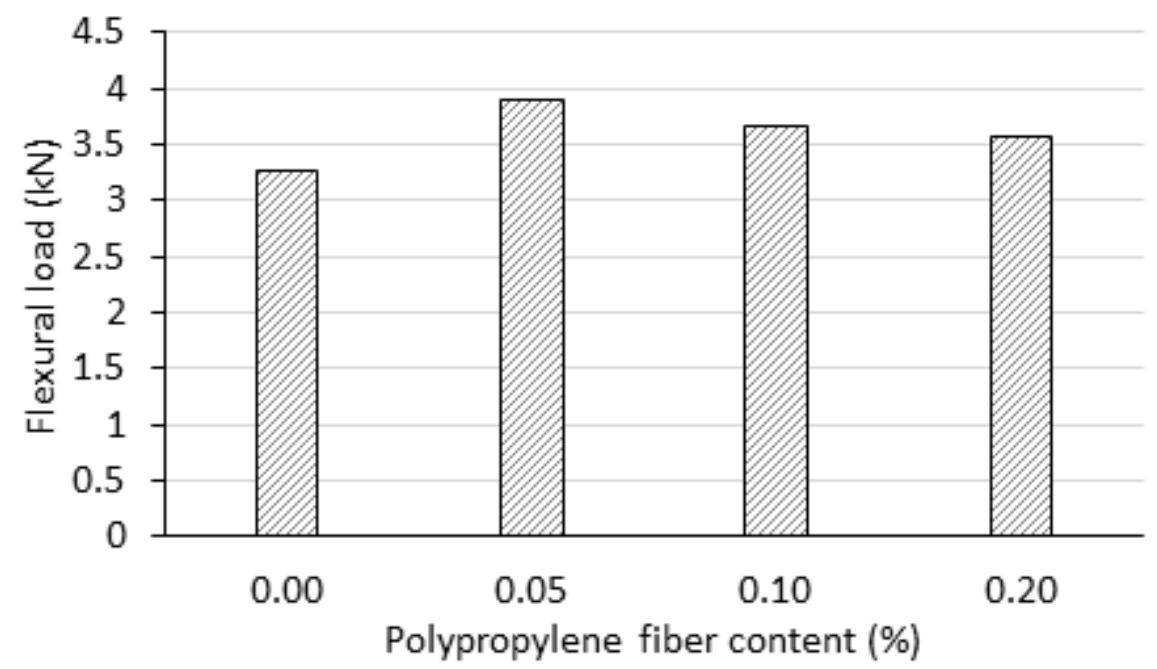

Figure 2: Flexural strength of cement mortar with Polypropylene fibres 
Table 1: Mechanical strengths results

\begin{tabular}{|c|c|c|}
\hline Specimen & Compressive strength (MPa) & Flexural capacity (kN) \\
\hline Control & 48.5 & 3.28 \\
\hline $0.05 \%$ fiber content & 57.5 & 3.89 \\
\hline $0.1 \%$ fiber content & 61.3 & 3.67 \\
\hline $0.2 \%$ fiber content & 52.0 & 3.57 \\
\hline
\end{tabular}

On the other hand, adding polypropylene fibers improved the integrity of the hardened mortar and held the broken parts together after failure as shown in Figure 3.

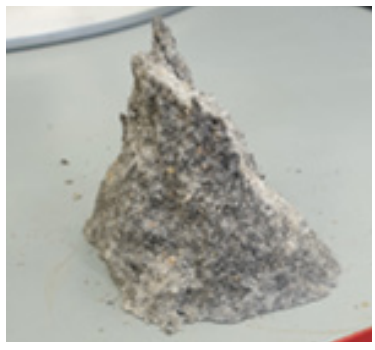

(a)

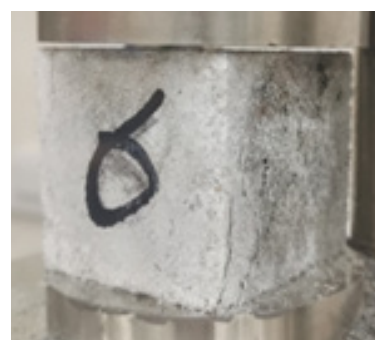

(b)

Figure 3: Failure mode (a) control specimen (b) mortar with fibers

\section{CONCLUSION}

1. Adding polypropylene fibers into cement mortar improved its compressive strength. The maximum improvement was noticed in the case of using $0.1 \%$ fibers content, which was equal to $26 \%$ compared to the control specimen.

2. Adding polypropylene fibers into cement mortar improved its flexural strength. The maximum improvement was noticed in the case of using $0.05 \%$ fibers content, which was equal to $19 \%$ compared to the control specimen.

3. Cement mortar specimens with polypropylene fibers have ductile failure mode compared to brittle failure for control specimens.

\section{REFERENCES}

Li, L. G., Chu, S. H., Zhu, K. L. J. \& Kwan, A. K. H. (2018). Roles of water film thickness and fibre factor in workability of polypropylene fibre reinforced mortar. Cem. Concr. Compos, 93 196-204. https://doi.org/10.1016/j.cemconcomp.2018.07.014.

Li, L. G., Zhao, Z. W., Zhu, J., Kwan, A. K. H. \& Zeng, K. L. (2018). Combined effects of water film thickness and polypropylene fibre length on fresh properties of mortar. Constr. Build. Mater, 174 586-593. https://doi.org/10.1016/j.conbuildmat.2018.03.259.

Mohseni, E., Khotbehsara, M. M., Naseri, F., Monazami, M. \& Sarker P. (2016). Polypropylene fiber reinforced cement mortars containing rice husk ash and nano-alumina. Constr. Build. Mater, 111 429-439. https://doi.org/10.1016/j.conbuildmat.2016.02.124.

Nunes, V. A., Borges, P. H. R. \& C. Zanotti (2019). Mechanical compatibility and adhesion between alkali-activated repair mortars and Portland cement concrete substrate. Constr. Build. Mater, 215 569-581. https://doi.org/10.1016/j.conbuildmat.2019.04.189. 
Szeląg M. (2019). Evaluation of cracking patterns of cement paste containing polypropylene fibers. Compos. Struct, 220, 402-411. https://doi.org/10.1016/j.compstruct.2019.04.038.

Zanotti, C., Borges, P. H. R., Bhutta, A. \& Banthia, N. (2017). Bond strength between concrete substrate and metakaolin geopolymer repair mortar: Effect of curing regime and PVA fiber reinforcement. Cem. Concr. Compos, 80 307-316. https://doi.org/10.1016/j. cemconcomp.2016.12.014.

Cite this article as: Irshidat M. R., Al Nuaimi N., Salim S., Rabie M., "Dosage Optimization of 